\title{
Spotted hyaena visitation at anthropogenic sites in the Kruger National Park, South Africa
}

\author{
Lydia E. Belton ${ }^{1}$, Elissa Z. Cameron ${ }^{1,2,3}$ and Fredrik Dalerum ${ }^{1,4,5, *}$ \\ ${ }^{1}$ Mammal Research Institute, Department of Zoology and Entomology, University of Pretoria, \\ Pretoria, South Africa \\ ${ }^{2}$ School of Biological Sciences, University of Canterbury, Christchurch, New Zealand \\ ${ }^{3}$ School of Zoology, University of Tasmania, Hobart, Australia \\ ${ }^{4}$ Research Unit of Biodiversity (UO, CSIC, PA), University of Oviedo, Mieres Campus, Mieres, Spain \\ ${ }^{4}$ Department of Zoology, Stockholm University, Stockholm, Sweden \\ * Corresponding author, e-mail: dalerumjohan@uniovi.es
}

Many large carnivores are attracted to anthropogenic sites, typically because they offer easy access to anthropogenic resources such as garbage. Such behaviour could lead to increased contacts between people and carnivores, with the potential for escalated conflicts. Within protected areas, carnivores experience limited risks of visiting anthropogenic sites. However, conflict could still arise, so that it is important to evaluate the drivers for visitation within protected areas. We tested how age, sex and social rank influenced seasonal visitation rates by spotted hyeanas (Crocuta crocuta) at two sites with elevated human activity and infrastructure within the Kruger National Park, South Africa. Social rank did not influence visitation rates, and differences among age classes did not correspond to differences in abilities to procure native food. Instead, juveniles had higher visitation rates than older individuals, but only during the wet season. Visitation rates were not consistently higher during the dry season, nor was there more pronounced differences between age classes in the dry season. Our results suggest the anthropogenic sites were visited as part of exploratory behaviour coupled with occasional rewards. Our study also showed a large individual variation in tendencies towards visiting anthropogenic sites, but only for younger animals. We call for further studies quantifying individual variation in tendencies to visit anthropogenic sites, and argue that deterrents and limitations in rewards of visiting anthropogenic sites may be efficient in preventing humanhyaena conflict within the Kruger National Park.

Keywords: anthropogenic resources, Carnivora, exploratory behaviour, protected areas, Crocuta crocuta

African Zoology 2018 53(3): 113-118 


\section{Introduction}

Generalist mesocarnivores and omnivores frequently visit sites of high human activity (anthropogenic sites), typically because of easy access to anthropogenic resources such as waste, shelter or water (Bateman and Fleming 2012). Such close coexistence between humans and carnivores may lead to conflict (Madden 2004), for instance related to increased carnivore damages to proparty and live-stock (Treves and Karanth 2003) but also related to direct attacks to humans (Penteriani et al. 2016). Many studies have focused on carnivore visits at anthropogenic sites outside protected areas (Fedriani et al. 2001; Holmern et al. 2007; Abay et al. 2010; Yirga et al. 2015). However, anthropogenic environments may also occur on protectad land, where persecution is often lower relative to on unprotected land (e.g., Swanepoel et al. 2015). Yet, conflict between carnivores and human interests may still increase inside protected areas if carnivores start to become more active around human settlements. This is particularly true for large carnivores, which may present a direct safety risk for humans (Penteriani et al. 2017). Understanding the motivations for visiting anthropogenic sites is beneficial for designing optimal management strategies for minimizing conflict, particularly since there may also be benefits in having wildlife visit anthropogenic sites related to increased opportunities for close observations by tourists.

The spotted hyaena (Crocuta crocuta), is a large group living carnivore which is often persecuted outside of protected areas (Holmern et al. 2007). Spotted hyaenas both hunt and scavenge for native food (Hayward 2006). They also visit anthropogenic sites (Kolowski and Holekamp 2008; Abay et al. 2010; Yirga et al. 2010; Yirga et al. 2015), although they do not always seem do so to directly access anthropogenic resources (Belton et al. 2016). However, in a recent study, Belton et al. (2018a) suggested that there may be a large individual variation in the utilization of resources associated with anthropogenic sites. Spotted hyaenas live in social groups (clans), which follow a strictly matriarchal structure being dominated by a dominant female followed by a linear hierarchy in the rank of other females and their sub-adult offspring (Kruuk 1972; Frank 1986). Males disperse between the ages of two and six (Holekamp and Dloniak 2010), and immigrant males follow a linear hierarchy which is below all females and their offspring (East and Hofer 2001). Within this male hierarchy dominance is based on tenure. In this study, we investigated visitation rates at anthropogenic sites by spotted hyaenas of different sex, age and rank in the Kruger National Park (KNP), South Africa, and if there was a seasonal variation in visitation rates.

\section{Methods}

The KNP is situated in the north eastern corner of South Africa and covers almost $20,000 \mathrm{~km}^{2}$. Our study focused on two sites, the Skukuza tourist camp and staff village (31 $35^{\prime} 34.323^{\prime \prime} \mathrm{E}$, $\left.24^{\circ} 59^{\prime} 43.625^{\prime \prime S}\right)$ and the Afsaal picnic site ( $\left.31^{\circ} 32^{\prime} 0.15^{\prime \prime} \mathrm{E}, 2^{\circ} 17^{\prime} 24.217^{\prime \prime S}\right)$. Both sites lie in the southern section of the KNP (Fig. 1). Southern KNP falls within the lowveld bioregion (Mucina and Rutherford 2006). Vegetation is dominated by Clerocarya caffra and Senegalia nigrescens, with Combretum species being dominant on granite based soils. Rainfall is seasonal with the majority falling between October and March, with a peak in January and February (Venter et al. 2003). KNP hosts a diverse array of herbivorous and carnivorous mammals (Belton et al. 2018a).

We conducted the study between May 2007 and December 2009 on two spotted hyaena clans, one inhabiting the area surrounding Skukuza (SK) and one the area around Afsaal (AF). We defined data from October through March as having been collected during the wet season and data from April through September to have been collected during the dry season (Venter et al. 
2003). The SK clan had free access to the unfenced staff village consisting of 250 houses, an enclosed staff compound, a golf course, a shop, communal areas, as well as administrative buildings beside an enclosed area with tourist accommodation (Belton et al. 2016). The staff area combined with the rest camp covers $4.3 \mathrm{~km}^{2}$ and houses approximately 2300 staff (Foxcroft et al. 2008). Fences around both individual houses and the compound prevented easy access to household rubbish bins. However, rubbish bins in communal areas and larger waste collection sites were unfenced. The number of larger waste collection sites varied over time, although the site that was used to dispose of restaurant scraps was permanently in place. Open gates and damaged fencing also allowed for opportunistic access to other rubbish bins. SK hyaenas also had access to the unfenced car park of a picnic site which contained rubbish bins and they were able to walk along the perimeter fence of the tourist rest camp. The Afsaal picnic site consists of a shop, a cafeteria and a picnic area, all of which are unfenced, with an adjoining fenced residence typically housing four to five staff. However, levels of human activity are substantially lower than in the Skukuza complex (Belton et al. 2018a). Permanent water sources exist in the vicinity of both sites. Visitors are required to return to a camp or leave the park by a specific time that varies throughout the year to coincide with sunset, and members of staff do not walk in unfenced areas after dark. Animals were therefore able to visit unfenced anthropogenic areas after dark with minimal disturbance.

We observed clans at communal den sites adjacent to the anthropogenic sites to assess clan size and composition, as well as to record the sex, age and social rank of each animal (Belton et al. 2018b). These observations were conducted throughout the study period and augmented with observations of the clans whenever they were encountered opportunistically (Belton et al. 2018b). All individuals in both clans were individually recognizable by their unique spot patterns and each individual was sexed based on the shape of the phallic glands (Frank et al. 1990). Animals were categorised into four age classes: juvenile ( $<14$ months), sub-adult (14-24 months), young adult (25-48 months) and adult ( $>48$ months). For animals with unknown birth dates we based age estimations on pelage and size, which were confirmed retrospectively by comparing photos of animals with unknown age to those with a known birth date (Belton et al. 2018b). We used the average weaning age recorded for east African spotted hyaenas, 14 months (Holekamp et al. 1996, Boydston et al. 2005). We classed juveniles and sub-adults separately to facilitate an evaluation of any effects of lactation on visitation rates. Since spotted hyaenas are born at a natal den and typically move to a communal den at an age of 0-4 weeks (Holekamp et al. 1997), our age estimates of birth dates are accurate to within a month. Rank was defined from the outcomes of dyadic interactions and leg lifting during ritualised greeting displays (Belton et al. 2018b). Females and natal males (juveniles, sub-adults and young adults) were classed as high or low ranked (Kolowski and Holekamp 2008). We assigned all males past dispersal age (i.e. adults) to a separate immigrant class which we regarded to be subordinate to all females and natal males. We excluded any juveniles that we only observed at the communal den from the rank estimations, as well as any individuals that were never sighted at the communal den or were only recorded once within each home range. In both clans twenty animals moved between age groups, whilst no animals were observed to move between the broad rank categories high and low.

We recorded visitation from direct observations at either the Skukuza rest camp or the Afsaal picnic site. Observations were made with the aid of hand-held spot-lights. The data were restricted to the presence or absence of each clan member at each observation session, since dense vegetation in Skukuza and the layout of Afsaal did not allow us to reliably record times of arrival or departure, or to make detailed and meaningful observations of individual behaviour. We conducted 24 observation sessions in Skukuza between September 2007- December 2009 (16 in 
the wet and 8 in the dry season) and 21 observation sessions in Afsaal between June 2008 September 2009 (16 in the wet and 5 in the dry season). To allow for temporal independence between observations we allowed a minimum of one week between each observation period at each site. Although this probably is a larger time interval than what can be regarded as independent sampling based on hyaena movement patterns (e.g., Belton et al. 2016), we preferred to keep this long interval between our observation to ensure that we did not included any temporal dependencies in our data. At Skukuza, a 400 meter section of the camp fence perimeter adjacent to a camping area was selected for observation. We selected this site since the complex structure of the village prevented us from monitoring the whole area. Anecdotal observations suggested that hyaenas that we opportunistically observed throughout the Skukuza village all utilized this site. We therefore argue that observations at this site provide a representative sample of hyaena activity within Skukuza. In Afsaal, we simultaneously monitored the picnic site and staff residences. Observations in Skukuza lasted for two hours, beginning 30 minutes after the closing of rest camp gates at sunset. This was chosen to coincide with visitors having returned to the camp and beginning to prepare food. Observations in Afsaal commenced at dusk but only continued for one hour due to logistic constraints. At each observation session, all animals observed were recorded as present. Data from a pilot study suggested that animals mainly used these sites at dusk. In addition, we repeatedly visited the Afsaal site during other times of the night, but none of these visits revealed other animals at the site than those recorded at dusk. Therefore, we believe that our observation periods gave a representative sample of visitation at each site, despite the different observation times. On three occasions individuals were seen at the Skukuza site but could not be identified with any certainty. These individuals were not included in the analysis.

The probabilities that individual animals were present at anthropogenic sites were analysed using a generalised linear mixed model ( $\mathrm{g} / \mathrm{mm}$ ) with a binomial error structure and logit link function. The model used the proportion of observation nights for which a given individual was present at the anthropogenic resource site as the response variable. We opted for this linear modelling approach because it intrinsically estimates effects of our predictors on the probability of presence (McCullagh and Nelder 1989), as well as allow for the control of our interdependence structure caused by animals shifting age groups and also reside in the same clan (Zuur et al. 2009). We calculated this proportion as the number of observation nights a given clan member was observed at a resource site divided by the total number of possible nights that individual could have been at the resource. Total number of possible observation nights was defined as all observation events during which an animal was confirmed as alive and a clan member of a specific age or rank category. An animal was defined as dead or dispersed if it had not been seen for a minimum of three months before the end of the study, but we used the last date it was observed alive to define its clan membership. Rank, sex, age, and season were included as categorical fixed effects, as well as two way interactions between season and rank, sex and age. We included individual nested within clan as a random effect structure. Since clan identity and site were completely confounded we did not include site in our model. We regard this as appropriate since we were primarily focusing the analyses on contrasts between age, sex and rank classes, and regarded the clans to be our independent unit of observation. Any additional variation between sites would then only increase the variance around these estimates, which justifies the inclusion of clan as a random term. Fixed terms were evaluated using sequential likelihood ratio tests (Pawitan 2013), which is more reliable than Wald statistics for limited sample sizes (Agresti 2007). We followed an analogue to a type II sum of squares approach, in which a model including a specific term was evaluated against a candidate model containing all other terms at the same level of 
complexity (Hector et al. 2010). Multiple comparisons of means were carried out using pair wise contrasts on predicted marginal means with the alpha error adjusted for multiple comparisons following Benjamini and Hochberg (1995). Following Fisher (1935), threshold for statistical significance was set to $p=0.05$. Statistical analyses were conducted using $R$ version 3.4.4 for Linux (http://www.r-project.org), and the user contributed packages Ime4 (version 1.1-7; Bates et al. 2015) and Ismeans (Lenth 2016).

\section{Results}

In total, we identified 29 individual animals in the SK and 25 in the AF clan (Table 1). At SK we recorded visits of 16 of the 29 individuals at anthropogenic resource sites (10 during the wet and 14 during the dry season), and visits of 9 of 25 individuals at AF ( 7 during the wet and 5 during the dry season). At SK we recorded an average of $2.6( \pm 1 \mathrm{sd}=1.6)$ animals per observation night during the wet and 2.4 ( $\pm=1.6$ ) during the dry season. Corresponding values at AF were 1.1 ( $\pm=$ 1.7) and $2.8( \pm=2.5$ ) animals per observation night for the wet and dry season, respectively. We did not observe any individuals that we clearly identified to not have been from the resident clans, although three individuals were observed at SK that could be identified with certainty.

There was a significant interaction effect of age and season on the probability that individual clan members would visit anthropogenic resource sites $\left(\chi^{2}=7.94, \mathrm{df}=3, \mathrm{P}=0.05\right)$, but no significant interactions between season and either $\operatorname{sex}\left(\chi^{2}=2.28, \mathrm{df}=1, \mathrm{P}=0.13\right)$ or $\operatorname{rank}\left(\chi^{2}=\right.$ $0.10, d f=2, P=0.95)$. There were no significant main effects of either $\operatorname{sex}\left(\chi^{2}=1.81, d f=1, P=\right.$ 0.18 ) or rank $\left(X^{2}=1.13, d f=1, P=0.57\right)$ on visitation probabilities. There was a significant higher mean probability that for juveniles to visit anthropogenic resource sites than young adults during the wet season (Table 2), and there were tendencies for both juveniles and sub-adults to have higher probabilities to visit anthropogenic resource sites than young adults and adults (Fig. 2). For both juveniles and sub-adults, there appear to have been higher individual variation in visitation probabilities than for young adults and adults (Fig. 2).

\section{Discussion}

We interpret our observations as an indication that the anthropogenic sites in the KNP were not primarily visited by spotted hyeanas for nutritional purposes, but rather as part of exploratory behaviour. Exploratory behaviours are usually more prevalent in young animals (Stamps and Groothius 2010). and have previously been observed both in spotted hyaenas (Benson-Amram and Holekamp 2012) and in other carnivores (Bekoff 1989). Such an interpretation supports parallel studies in the KNP which have pointed to limited direct benefits from anthropogenic food (Belton et al. 2016; Belton et al. 2018a). We found no effect of social rank on visitation probabilities at the two anthropogenic sites, and our observations suggested that juveniles and to some extent subadults had the highest probabilities of visiting the anthropogenic sites, but primarily during one season. We therefore argue that the patterns of visitation at anthropogenic resource sites in KNP did not follow what could be predicted based on age and rank related ability to hunt and procure food. In addition, we did not find any seasonal differences in the visitation rates of animals of contrasting sex, age and rank classes, which lends further support to a limited nutritional motivation for the visits.

Since our results suggest that spotted hyaenas may not have visited these sites because of any nutritional need for alternative food, we suggest that increasing the perceived risk of visitation, coupled with a removal of any occasional rewards may be effective in miniminzing conflict associated with hyaena visits. Several mechanisms have been suggested for such deterrent effects, ranging from sensory deterrents to technologically advanced methods of real time virtual 
fences (Jachowski et al. 2014). Strict garbage control and strict enforcement of appropriate visitor behaviour could be efficient in minimizing potential rewards. We suggest that ethical and efficient mechanisms are developed for the KNP, as these likely will be efficient in preventing conflict between hyaenas and people inside the park.

We recognise several potential limitations with our study. We only recorded visitation to the general areas surrounding the anthropogenic resource sites, and not directly the presence at specific locations of access to anthropogenic resources (e.g., garbage bins). However, we do not believe this shortcoming to have been serious. Our monitoring of the general area of the anthropogenic sites is likely to have given a representative overview of which animals that were present at these sites, although we acknowledge that it may have been difficult to draw firm conclusions from our data regarding the motivation for the visits. We also used two sites with large variation in human activity and infrastructure (Belton et al. 2018a,b). Such variation could obviously have influenced the relative tendencies between animals of different sex, rank and age towards visiting anthropogenic sites, and also the constellation of social groups at potential visits. However, the amount of human infrastructure and activity did not appear to have influenced the incorporation of anthropogenic material in spotted hyaena diets (Belton et al. 2018a). Finally, we acknowledge that our study was conducted on only two clans, and hence that our statistical power was low. We therefore encourage further studies that manage to simultaneously observe multiple clans and how they respond to anthropogenic alterations to the environment.

To conclude, our study at two anthropogenic resource sites in Kruger National Park, South Africa, did not suggest that hyaenas visited these sites in relation to rank and sex specific ability to procure food. Instead, anthropogenic sites were visited primarily by juveniles and sub-young adults, who were not yet independent from their mothers. We interpret the observed visits as part of exploratory behaviour that may have been reinforced by occasional rewards. However, our results also point to a large individual variation in tendencies towards visiting anthropogenic sites, but only for young animals. We call for further studies quantifying anthropogenic resource use by large carnivores, especially studies inside of protected areas as well as studies evaluating individual variation in tendencies towards utilization. We subsequently suggest that management action including deterrent at anthropogenic sites coupled with limiting any occasional rewards may provide effective methods to prevent human-hyaena conflict inside the KNP.

\section{Acknowledgements}

Research was approved by the University of Pretoria Animal Use and Care Committee (protocol number EC010-07) and the Kruger National Park Animal Use and Care Committee. Funding was provided by the National Research Foundation (incentive funding for rated researchers awarded to to EZC and FD), by the University of Pretoria (incentive funding for rated researchers awarded to EZC and FD and a research fellowship awarded to FD) and by the Spanish Ministry of Economy and Competitiveness (research fellowship awarded to FD). The authors declare that they have no financial or personal relationships that may have inappropriately influenced them in writing this article.

\section{References}

Abay GY, Bauer H, Gebrihiwot K, Deckers J. 2010. Peri-urban spotted hyena (Crocuta crocuta) in Northern Ethiopia: diet, economic impact, and abundance. European Journal of Wildlife Research 57: 759-765.

Agresti A. 2007. An introduction to categorical data analysis (2nd edition). Hoboken, NJ: John Wiley \& Sons. 
Bateman PW, Fleming PA. 2012. Big city life: carnivores in urban environments. Journal of Zoology, London 287: 1-23.

Bates D, Maechler M, Bolker BM, Walker SC. 2011. Fitting linear mixed effect models using Ime4. Journal of Statistical Software 67: 1-48.

Belton L, Cameron EZ, Dalerum F. 2016. Spotted hyaena space use in relation to human infrastructure inside a protected area. PeerJ 4: e2596.

Belton L, Cameron EZ, Dalerum F. 2018a. Anthropogenic influences on spotted hyaena diet in the Kruger National Park, South Africa. Mammal Research 63: 315-323.

Belton L, Cameron EZ, Dalerum F. 2018b. Social networks of spotted hyaenas in areas of contrasting human activity and infrastructure. Animal Behaviour 135: 13-23.

Benjamini Y, Hochberg Y. 1995. Controllin gthe false discovery rate: a practical and apowerful approach to multiple hypothesis testing. Journal of the Royal Statistical Society, Series B 57: 289-300.

Bekoff M. 1989. Behavioural development of terrestrial carnivores. In: Gittleman JL (ed). Carnivore behaviour, ecology and evolution, Volume 1. New York: Cornell University Press. pp 89-124.

Benson-Amram S, Holekamp KE. 2012. Innovative problem solving by wild spotted hyenas. Proceedings of the Royal Society Series B Biology 279: 4087-4095.

Boydston EE, Kapheim KM, Van Horn RC, Smale L, Holekamp KE. 2005. Sexually dimorphic patterns of space use throughout ontogeny in the spotted hyena (Crocuta crocuta). Journal of Zoology 267: 271-281.

Fedriani JM, Fuller TK, Sauvajot RM 2001. Does availability of anthropogenic food enhance densities of omnivorous mammals? An example with coyotes in southern California. Ecography 24: 325-331.

Fisher RA 1935. The design of experiments ( $8^{\text {th }}$ edition, 1966). New York: Hafner Press.

Foxcroft LC, Richardson DM, Wilson JRU. 2008. Ornamental plants as invasive aliens: problems and solutions in Kruger National Park, South Africa. Environmental Management 41: 32-51.

Frank LG 1986. Social organization of the spotted hyaena Crocuta crocuta. II. Dominance and reproduction. Animal Behaviour 34: 1510-1527.

Frank LG, Glickman SE, Powch I. 1990. Sexual dimorphism in the spotted hyaena (Crocuta crocuta). Journal of Zoology 221: 308-313.

Hayward M. 2006. Prey preferences of the spotted hyaena (Crocuta crocutta) and degree of dietary overlap with lions (Panthera leo). Journal of Zoology 270: 606-614.

Hector A, von Felten S, Schmid B. 2010. Analysis of variance with unbalanced data: an update for ecology \& evolution. Journal of Animal Ecology 79: 308-316.

Holekamp KE, Dloniak SM. 2010. Intraspecific variation in the behavioral ecology of a tropical carnivore, the spotted hyaena. Advances in the Study of Behavior 42: 189-229.

Holekamp KE, Smale L, Berg R, Cooper SM. 1997. Hunting rates and hunting success in the spotted hyena (Crocuta crocuta). Journal of Zoology 242: 1-15.

Holekamp KE, Smale L, Szykman M. 1996. Rank and reproduction in the female spotted hyaena. Journal of Reproduction and Fertility 108: 229-237.

Holmern T, Nyahongo J, Røskaft E. 2007. Livestock loss caused by predators outside the Serengeti National Park, Tanzania. Biological Conservation 135: 518-526.

Kolowski JM, Holekamp KE. 2008. Effects of an open refuse pit on space use patterns of spotted hyenas. African Journal of Ecology 46: 341-349.

Kruuk H. 1972. The spotted hyena: a study of predation and social behavior. Brattleboro, Vermont: Echo point books.

Lenth RV. 2016. Least square means: The R package Ismeans. Journal of Statistical Software 69: 1- 
33.

McCullagh P, Nelder JA. 1989. Generalized linear models (Second edition). London: Chapman \& Hall.

Mucina L, Rutherford MC (eds). 2006. The vegetation of South Africa, Lesotho and Swaziland. SANBI, Pretoria, South Africa.

Penteriani V, Bombieri G, Fedriani JM, Lopez-Bao JV, Garrote PJ, Russo LF, Delgado MD. 2017. Humans as prey: coping with large carnivore attacks using a predator-prey interaction perspective. Human-wildlife Interactions 11: 192-207.

Penteriani V, del Mar Delgado M, Pinchera F, Naves J, Fernández-Gil A, Kojola I, Härkönen S, Norberg H, Frank J, Fedriani JM, Sahlén V, Støen OG, Swenson JE, Wabakken P, Pellegrini P, Herrero S, López-Bao JV. 2016. Human behaviour can trigger large carnivore attacks in developed countries. Scientific Reports 6: 20552.

Stamps J, Groothuis TGG. 2010. The development of animal personality: relevance, concepts and perspectives. Biological Reviews 85: 301-325.

Swanepoel L, Somers MJ, Van Hoven W, Scheiss-Mejier M, Owen C, Snyman A, Martins Q, Camacho G, Boshoff W, Dalerum F. 2015. Survival in southern African leopard populations. Oryx 49: 595-603.

Treves A, Karanth U. 2003. Human-carnivore conflict and perspectives on carnivore management worldwide. Conservation Biology 17: 1491-1499.

Venter FJ, Scholes RJ, Eckhardt HC. 2003. The abiotic template and its associated vegetation patterns. In: Du Toit JT, Rogers KH, Biggs HC (eds.). The Kruger experience: ecology and management of savanna heterogeneit. Washington DC: Island Press. pp 83-129.

Yirga G, Leirs H, De longh HH, Asmelash T, Gebrehiwot K, Deckers J, Bauer H. 2015. Spotted hyena (Crocuta crocuta) concentrate around urban waste dumps across Tigray, northern Ethiopia. Wildlife Research 42: 563-569.

Yirga G, De longh HH, Leirs H, Gebrihiwot K, Deckers J, Bauer H. 2010. Adaptability of large carnivores to changing anthropogenic food sources: diet change of spotted hyena (Crocuta crocuta) during Christian fasting period in northern Ethiopia. Journal of Animal Ecology 81: 1052-1055.

Zuur AF, leno EN, Walker NJ, Saveliev AA, Smith GM. 2009. Mixed effect models and extensions in ecology with R. New York: Springer. 
Table 1 Total number of observed animals of each age, sex and rank class in the Afsaal and Skukuza hyaena clans during both seasons combined as well as during the dry and the wet season. Some animals were only observed within a specific class for one season and some animals shifted age classes during the study. Therefore, this table does not add up to the total of 25 and 29 identified individuals in the Afsaal and Skukuza clan, respectively, but rather provides an indication of the total number of animals of each sex, age and rank that we based our analyses on.

\begin{tabular}{|c|c|c|c|c|c|c|c|c|c|c|c|c|c|c|c|c|c|c|}
\hline & \multicolumn{9}{|l|}{ Afsaal } & \multicolumn{9}{|c|}{ Skukuza } \\
\hline & \multicolumn{2}{|c|}{ Immigrant } & \multicolumn{3}{|c|}{ Low rank } & \multicolumn{3}{|c|}{ High rank } & \multicolumn{4}{|c|}{ Immigrant } & \multicolumn{2}{|c|}{ Low rank } & \multicolumn{4}{|c|}{ High rank } \\
\hline & Both & Dry & Wet & Both & Dry & Wet & Both & Dry & Wet & Both & Dry & Wet & Both & Dry & Wet & Both & Dry & Wet \\
\hline \multicolumn{19}{|l|}{$\underline{\text { Females }}$} \\
\hline Juveniles & & & & 1 & 1 & 1 & 5 & 5 & 0 & & & & 1 & 1 & 0 & 2 & 1 & 1 \\
\hline Sub-adults & & & & 3 & 3 & 1 & 0 & 0 & 0 & & & & 2 & 2 & 1 & 5 & 5 & 1 \\
\hline Young adults & & & & 1 & 1 & 1 & 2 & 2 & 2 & & & & 1 & 1 & 1 & 5 & 5 & 5 \\
\hline Adults & & & & 3 & 3 & 3 & 4 & 4 & 3 & & & & 3 & 3 & 2 & 5 & 4 & 4 \\
\hline \multicolumn{19}{|l|}{ Males } \\
\hline Juveniles & & & & 2 & 2 & 1 & 1 & 1 & 0 & & & & 2 & 2 & 0 & 3 & 3 & 3 \\
\hline Sub-adults & & & & 3 & 3 & 2 & 0 & 0 & 0 & & & & 4 & 4 & 0 & 4 & 2 & 3 \\
\hline Young adults & & & & 3 & 3 & 1 & 0 & 0 & 0 & 2 & 2 & 2 & 4 & 4 & 4 & 3 & 3 & 2 \\
\hline Adults & 4 & 4 & 2 & & & & & & & 4 & 4 & 4 & & & & & & \\
\hline
\end{tabular}


Table 2. Results of pair wise comparisons of the proportion of time spotted hyaenas of different age classes where observed at the anthropogenic resource sites during the dry and the wet season. Results are based on pair wise contrasts on predicted marginal means based on a generalized linear mixed model with a binomial error and logit link. Sample sizes for each group of animals are given in Table 1, and ranged from 1 to 10.

\begin{tabular}{llccccc}
\hline & \multicolumn{7}{c}{ Det season } \\
\cline { 2 - 7 } Contrast & Difference $^{\mathrm{a}}$ & $Z$ & $P_{a d j}{ }^{b}$ & Difference $^{\mathrm{a}}$ & $Z$ & $P_{a d j}^{b}$ \\
\hline Juveniles - Sub-adults & $-0.17 \pm 0.47$ & 0.36 & 0.72 & $1.50 \pm 0.82$ & 1.83 & 0.13 \\
Juveniles - Young adults & $0.74 \pm 0.49$ & 1.52 & 0.19 & $2.85 \pm 0.89$ & 3.20 & 0.01 \\
Juveniles - Adults & $1.69 \pm 0.95$ & 1.78 & 0.15 & $2.40 \pm 1.21$ & 1.98 & 0.13 \\
Sub-adults - Young adults & $0.91 \pm 0.47$ & 1.93 & 0.15 & $1.35 \pm 0.88$ & 1.54 & 0.19 \\
Sub-adults - Adults & $1.86 \pm 0.95$ & 1.97 & 0.15 & $0.90 \pm 1.21$ & 0.75 & 0.55 \\
Young adults - Adults & $0.95 \pm 0.94$ & 1.01 & 0.37 & $-0.45 \pm 1.01$ & 0.44 & 0.66
\end{tabular}

${ }^{a}$ Differences are given on a logit scale $\pm 1 \mathrm{SE}$

${ }^{\mathrm{b}}$ The alpha error was adjusted for multiple comparisons by controlling for the false discovery rate (Benjamini and Hochberg 1995) 


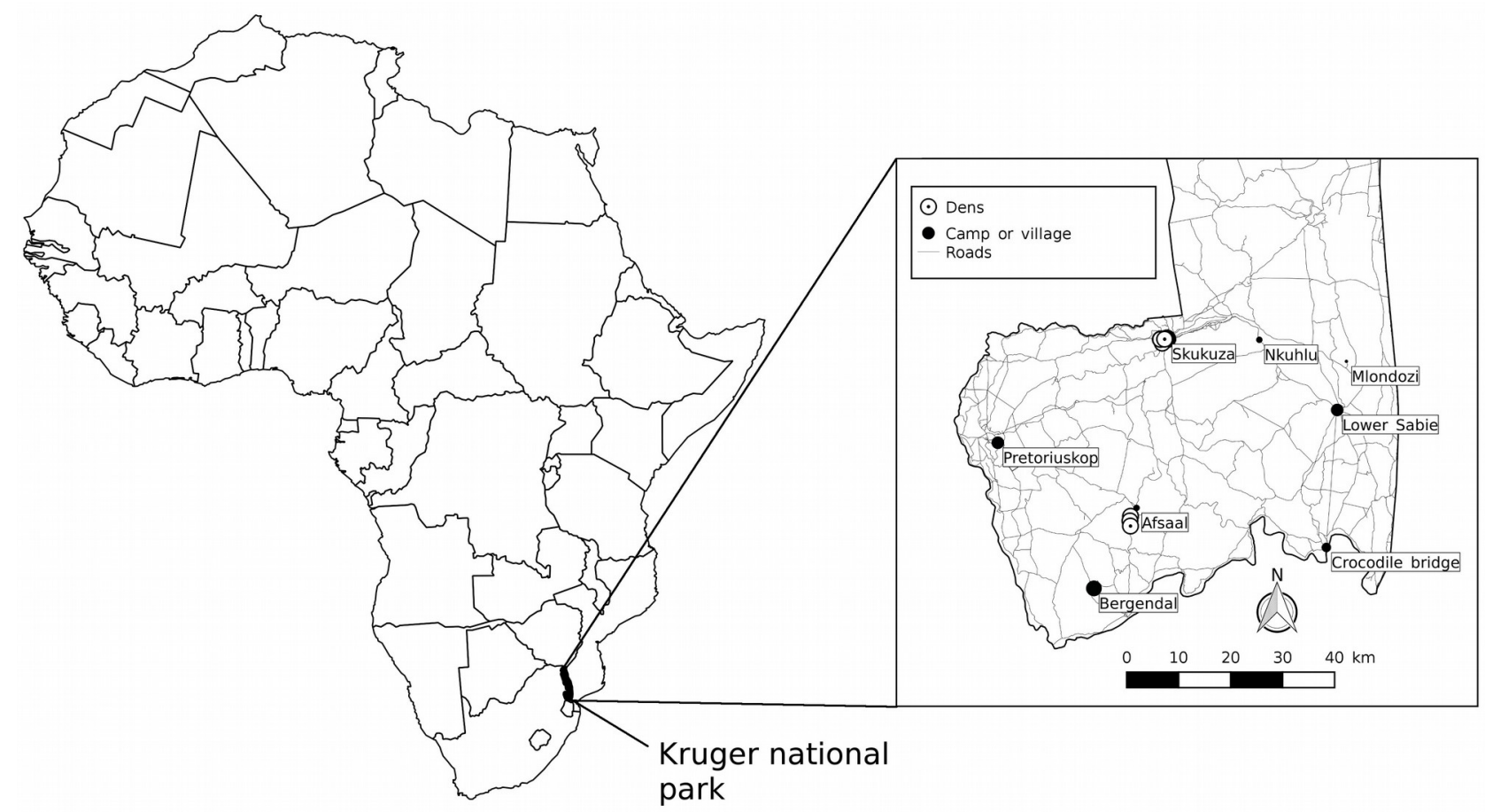

Figure 1. Location of the Kruger National Park within South Africa, the locations of the dens were the spotted hyaena clans in the vicinity of Afsaal (AF) rest camp and Skukuza (SK) village were observed, as well as the location and relative sizes of the villages and rest camps in the southern section of the Kruger National Park. 


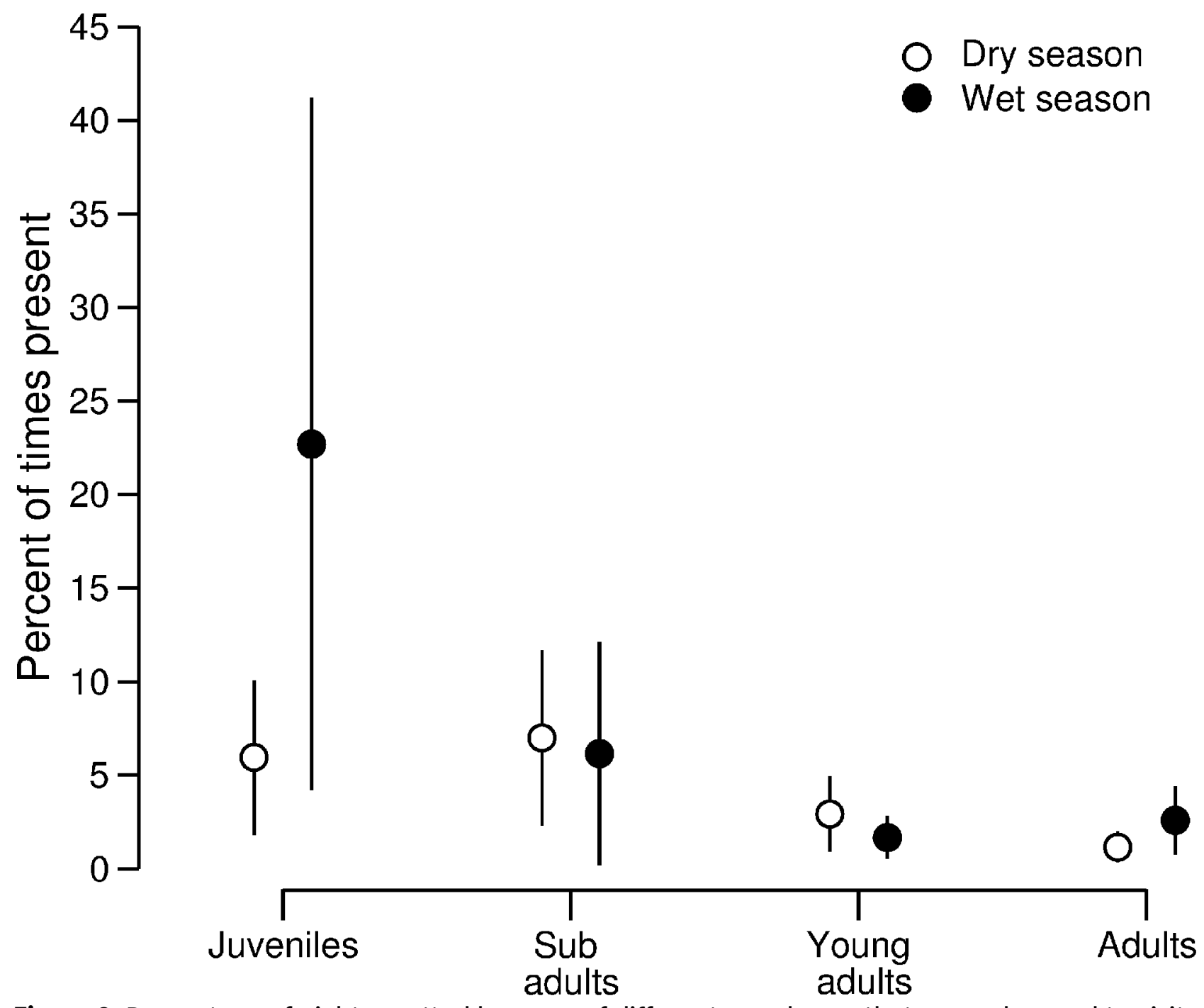

Figure 2. Percentage of nights spotted hyaenas of different age classes that were observed to visit two anthropogenic resource sites during the dry and the wet season in the Kruger National Park, South Africa. The percentages were based on number of observation events an animal was observed at a resource site divided by the total number of observation events that each individual could have been observed as a member of that age and rank class. The figure presents mean $\pm \mathrm{SE}$. 